\title{
Structuring West Germany's energy objectives
}

\author{
Ralph L. Keeney, Ortwin Renn and Detlof von \\ Winterfeldt
}

\begin{abstract}
For this article a comprehensive and politically legitimate list of criterla to evaluate energy systems was constructed from interviews with leading representatives of a broad spectrum of West German society. In the interviews, we probed the fundamental values of nine political and social organizations, including the Catholic and Lutheran Churches, the Federation of German Labour Unions, the Association of German Industries and the German Nature Society. A hierarchical representation of value criteria was logically structured for each group separately, and then aggregated into a combined 'value tree'. The result facilitates communication and constructive compromise, promotes the creation of policy options and helps evaluate future energy systems.
\end{abstract}

Keywords: West Germany's energy objectives; Value trees; Energy scenarios

Ralph L. Keeney is Professor of Systems Science and Detlof von Winterfeldt is Associate Professor of Systems Science with the Systems Science Department, Institute for Systems and Safety Management, University of Southern California, University Park, Los Angeles, CA 900890021, USA, and Ortwin Renn is an Associate Professor with the Center for Technology, Environment and Development (CENTED), Clark University, Worcester, MA 01610, USA.

We wish to thank the following interview partners for sharing their time and thoughts: Professor Dr Barthelmes, DNR; Dr Bauerschmitt, ÖKO; Dr Böke, BDI; Dr Dieschel, DNR; Dr John von Fryend, BDI; Dr Gabriel, DGB; Bishop Hemmerle, DKK; Dr Jeziorowski, DEK; Dr Knuth, DEK; Dr continued on $p 353$
The government of West Germany faces difficult decisions about the development of energy policy for the next 50 years. Oil and gas have become expensive and unreliable sources of energy. Nuclear power has encountered stiff public opposition which has recently gained strength through the participation of the 'Greens' in the West German parliament. The cost escalation of the fast breeder and the high temperature reactor projects casts doubt on the economic viability of these advanced technologies. Coal, while abundant, is expensive and requires government subsidies. Furthermore, burning coal has been linked to acid rain and the gradual deterioration of German forests. Conservation and solar and wind technologies have limits in technical feasibility and in economic viability. ${ }^{1}$

Recognizing these problems and the need for coordinated development of future energy systems, the West German parliament in 1978 created the Enquete Kommission 'Future nuclear energy policy'. This commission, which consists of seven members of parliament and eight scientific experts whose political affiliations were deliberately mixed, originally focused on nuclear power and decisions about development of the fast breeder reactor. The scope broadened when parliament charged the commission with studying alternative energy futures to "present the future possibilities and necessities for decision-making, considering ecological, economic, societal, and safety aspects both in a national and international context, and to develop corresponding recommendations'.

In response, the Enquete Kommission developed four alternative energy paths which represent very distinct economically and technically feasible developments of Germany's energy system during the coming decades. The paths vary from a high moderate growth scenario with a strong reliance on nuclear power to a moderate growth scenario with emphasis on conservation and renewable energy sources. To evaluate these energy paths, the commission categorized the major four criteria of a national energy system as economics, environmental, social, and international compatibility. Studies assessed the implications of the energy paths with respect to each of the four criteria. Since public opposition to nuclear energy and the rising concern with acid rain are 
major stumbling blocks for all energy paths, in-depth analysis was directed at public evaluation of the alternatives.

The present study was initiated by asking leaders in 10 major German organizations to participate in an effort to specify the criteria they felt to be appropriate for guiding German energy policy. After personally meeting leading representatives from each of the organizations, we had the opportunity to structure value trees with individuals in nine of the organizations. The results were aggregated to provide a comprehensive list of criteria meant to capture the significant concerns of German society as they would affect an energy system.

The effort described here has several potential uses for the Enquete Kommission. Firstly, it offers policy-makers a comprehensive catalogue of public concerns for evaluating alternative energy paths. Secondly, it helps to highlight the special interests of some important social groups in German society. Thirdly, it offers a basis for detailed assessment of public preferences regarding the impacts of energy options. Fourthly, and perhaps most importantly, it serves to focus discussion and promote constructive interaction for the purpose of developing appropriate energy policies for Germany.

\section{Overview of the value tree methodology}

Values are abstractions that help organize and guide preferences and are often expressed as statements about desired states, positive intentions, or preferred directions. The values of an individual or group pertaining to possible decisions are expressed in response to such questions as: What are your main objectives and concerns relating to the decisions to be made? What attributes or measures would be appropriate for differentiating between options? Why is a specified alternative either good or bad, desirable or undesirable? Using the responses, the analyst identifies and structures a hierarchy of values, referred to as a value tree, with general values and concerns at the top and specific criteria at the bottom. ${ }^{3,4}$

continued from $p 352$

Mahn, DEK; Dr Recker, RWE; Dr Riegert, DGB; Dipl Ing Rosenau, KWU; Professor Dr Schaefer, VDI; Dipl Ing Vennemann, KWU; Dr Vetter, VDI. The methodology and procedure for this study were developed with support from the Office of Naval Research with Contract No N0001481-C-0536 (Keeney) and from the National Science Foundation with grant No PRA8108638 (von Winterfeldt). The application was funded by the Kernforschungsanlage Jülich, GmbH, West Germany.

${ }^{1} \mathrm{M}$. Popp, 'German energy technology prospects', Science, Vol 218, 1982, pp 1280-1285.

Enquete Kommission, Zukünftige Kernenergie-Politik, Deutscher Bundestag, Bonn, 1980.

${ }^{3} \mathrm{D}$. von Winterfeldt and W. Edwards, Decision Analysis and Behavioural Decision Theory, Cambridge University Press, Cambridge, 1986.

${ }^{4}$ R.L. Keeney and H. Raiffa, Decisions with Multiple Objectives: Preferences and Value Tradeoffs, Wiley, New York, NY, 1976.
There are two approaches to generating value trees, namely top-down and bottom-up. The top-down approach is deductive and analytic, while the bottom-up approach is inductive and synthetic.

The top-down approach is based on an explication of the evaluators' most general values bearing on decisions of concern. The analyst asks the evaluators for their overall values first. Next, evaluators are asked to explain the meanings of their initial value categories and their inter-relationships. The discussion may indicate, for instance, that environmental damage is a major group objective for evaluating energy policies. The analyst pursues this by asking what is meant by environmental damage, why is it important, how is it affected by the energy options, and so on. The result of such an interview is a list of concerns articulated with logical principles but not in a structured manner. In the interview, it is not necessary to worry about consistency or double counting; it is more important to stretch the imagination to promote a wide spectrum of values. Part of the explication process is an exercise in semantics, inducing a significant clarification of meaning and understanding.

The bottom-up approach begins with the question, 'What are the criteria which distinguish between the objects being evaluated?' It is useful to begin by generating a large list of criteria. The initial focus 
should not be on logical consistency or redundancy, but rather on completeness. One way to create such a list is by articulating the good and bad aspects of a few alternatives. The analyst can also draw on previous studies that evaluated similar alternatives.

This initial list is then reduced by eliminating criteria that are not value relevant and expanded to include criteria for any 'holes' that can be identified. Next, groups of related criteria are aggregated into a higher-level value category. This clustering process is repeated for higher level values until a small number of general value areas are identified that cover the range of the original criteria list.

Having arrived at a preliminary value tree structure - either with the top-down or the bottom-up method - the analyst can appraise the tree structure by checking whether:

1. criteria explain the meaning of a general value category or relate in some other way (eg functional, means-end);

2. any criterion is included in more than one higher-level category;

3. the list of criteria is exhaustive; and

4. any criterion is redundant.

As a result, changes are inevitably made. The purpose is to create a value tree where the relationship between the lower-level criteria and higher-level categories is hierarchical and one of inclusion (by 1); avoids interdependencies between higher-level value categories (by 2); and creates an exhaustive (by 3 ) and non-redundant (by 4) list of criteria.

\section{Construction of individual value trees}

Our goal in asking distinct social groups to participate in structuring a value tree was to reach a wide spectrum of views on energy systems. There was no attempt to talk to all interested groups since the time and cost involved would be prohibitive. The 10 organizations asked to participate were the following:

BDI - Bund der Deutschen Industrie (Association of German Industries). As the head organization of industrial business associations in Germany, BDI is the spokesman for all German industry. Its membership consists of 37 industrial trade associations representing approximately 80000 private industrial enterprises.

DNR - Deutscher Naturschutzring (German Society for Nature Protection). The DNR combines a multitude of smaller environmental organizations with a total membership of over three million.

RWE - Rheinisch-Westfälisches Elektrizitätswerk GmbH (RhineWestphalia Electricity Company). RWE is a publicly held company with approximately 23000 employees, which supplies electricity to the heavily industrialized Ruhr area. It is the largest supplier of electricity in Germany with a capacity of 25000 MWe.

DKK - Deutsche Katholische Kirche (German Catholic Church). Approximately $40 \%$ of the 60 million citizens of Germany are members of the Catholic Church.

DEK - Deutsche Evangelische Kirche (German Lutheran Church). Approximately $50 \%$ of German citizens are members of the Lutheran Church.

VDI - Verband der Deutschen Ingenieure (Society of German Engineers). This society is the largest and most influential professional 
association of engineers in Germany, with a membership of about 200000.

$K W U-$ Kraftwerk Union (Power Plant United). KWU is a subsidiary of Siemens, a large industrial and commercial conglomerate employing more than 100000 people. KWU itself employs over 15000 individuals and is the largest firm building and selling coal and nuclear power plants in Germany.

DGB - Deutscher Gewerkschaftsbund (Federation of German Labour Unions). The DGB is the umbrella organization of all German labour unions with over 8 million members.

ÖKO - Ökologische Forschunginstitute (Ecological Research Institutes). An organization of several ecological research institutes, some of which have political programmes similar to those of the 'Greens' party. $B B U$ - Bund der Bürgerinitiativen Umwelt (Federation of Citizen Environmental Groups). The BBU combines a large and diverse number of citizens groups concerned with environmental issues, local and national politics, and the German peace movement.

A value tree was structured from discussions with from one to three individuals in the first nine organizations. After meeting with the board of BBU to explain the purpose of the project and our desire for their participation, they chose not to participate.

The interviews to obtain information in order to build value trees lasted between one and three hours and were conducted in German. Both top-down probing and bottom-up concepts were used to reduce the likelihood of significant values being omitted. To encourage participants to generate a broad spectrum of values and criteria, we stressed that there would be no attempt to assess the relative importance of values in this study.

After each meeting, we logically structured the content of the discussion into a preliminary value tree. This process involved clarifying meanings, identifying means-end relationships, and eliminating redundancies. We discussed the German material in English to structure the trees and thereby forced clearer thinking about the meaning of many criteria. The preliminary value trees were returned to each group with comments about the specific structuring logic. Each group was encouraged to discuss their trees with colleagues, to provide comments for revisions, and, in particular, to add values that might have been left out. The value trees discussed here have incorporated these revisions.

To conserve space, we focus here on two individual trees to communicate the scope of the discussions and to indicate some differences and similarities. Interestingly, most trees had similar value categories, indicating that all groups were concerned with the same basic objectives for energy systems. Groups differed by elaborating their main areas of concern in much more detail than concerns that were tangential to them.

Consider the value tree for the Association of German Industries (BDI) in Figure 1. Their major objectives concerning 'Development opportunities for the market economy' and 'Energy systems security' are thoroughly developed. The criteria under 'Development opportunities' are basically means to that higher end. They are conditions of the market economy that can be influenced by the energy system. The component criteria of 'Energy systems security' are a specification of its meaning rather than means to achieve security. The major objective of 'acceptance' is clearly articulated to include viewpoints of both majority 
Figure 1. Value tree for the Association of German Industries (BDI).
${ }^{5}$ Enquete Kommission, op cit, Ref 2.

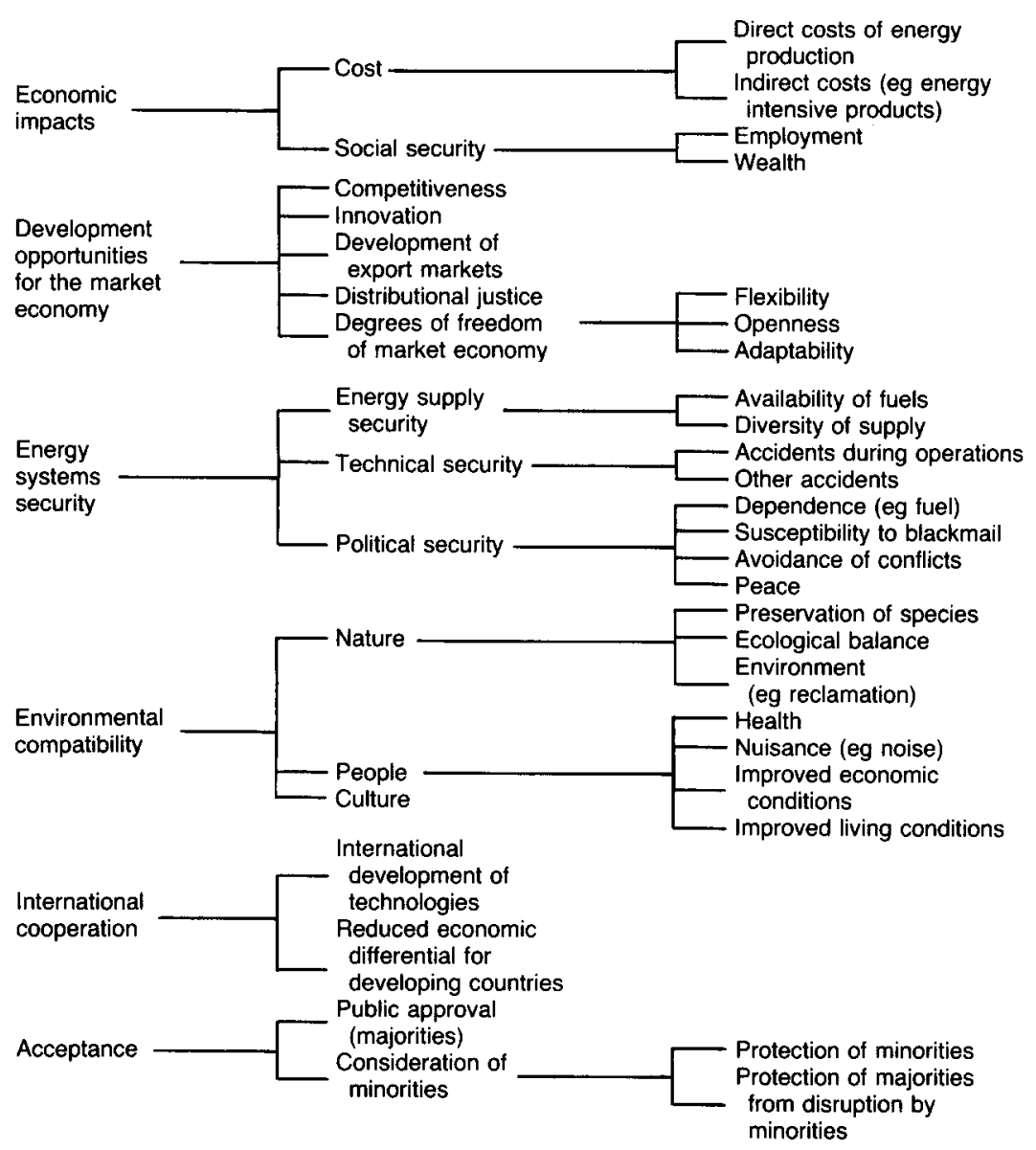

and minority groups. Implicit in this characterization is the interest in equity and fairness to all parties.

Moral and ethical concerns dominate in the value tree of the German Catholic Church (DKK) in Figure 2. There is a separation between 'relative' risks which our interview partner felt in principle could be traded off against benefits or other risks, and 'absolute' risks which threaten mankind. The same issue was raised during the interview with the Lutheran Church. Risks which have the potential to destroy mankind or the environment or endanger the process of coping with natural evolution were rejected as unacceptable regardless how unlikely they might be. Parts of the DKK value tree mention moral and social risks, including the dangers of uniformity, loss of fantasy, and of increased aggression. Finally, there is a separate concern for the basic values of the Church, which should be preserved and developed.

\section{The combined value tree}

It is essential that all values from individual trees be part of the combined value tree. Since there is presently no methodology to construct a combined tree from individual value trees, we developed what seemed to be a reasonable procedure as described after discussing the combined tree shown in Figure 3.

The eight general criteria correspond to the four criteria of the Enquete Kommission, ${ }^{5}$ namely economics, environmental compatibil- 


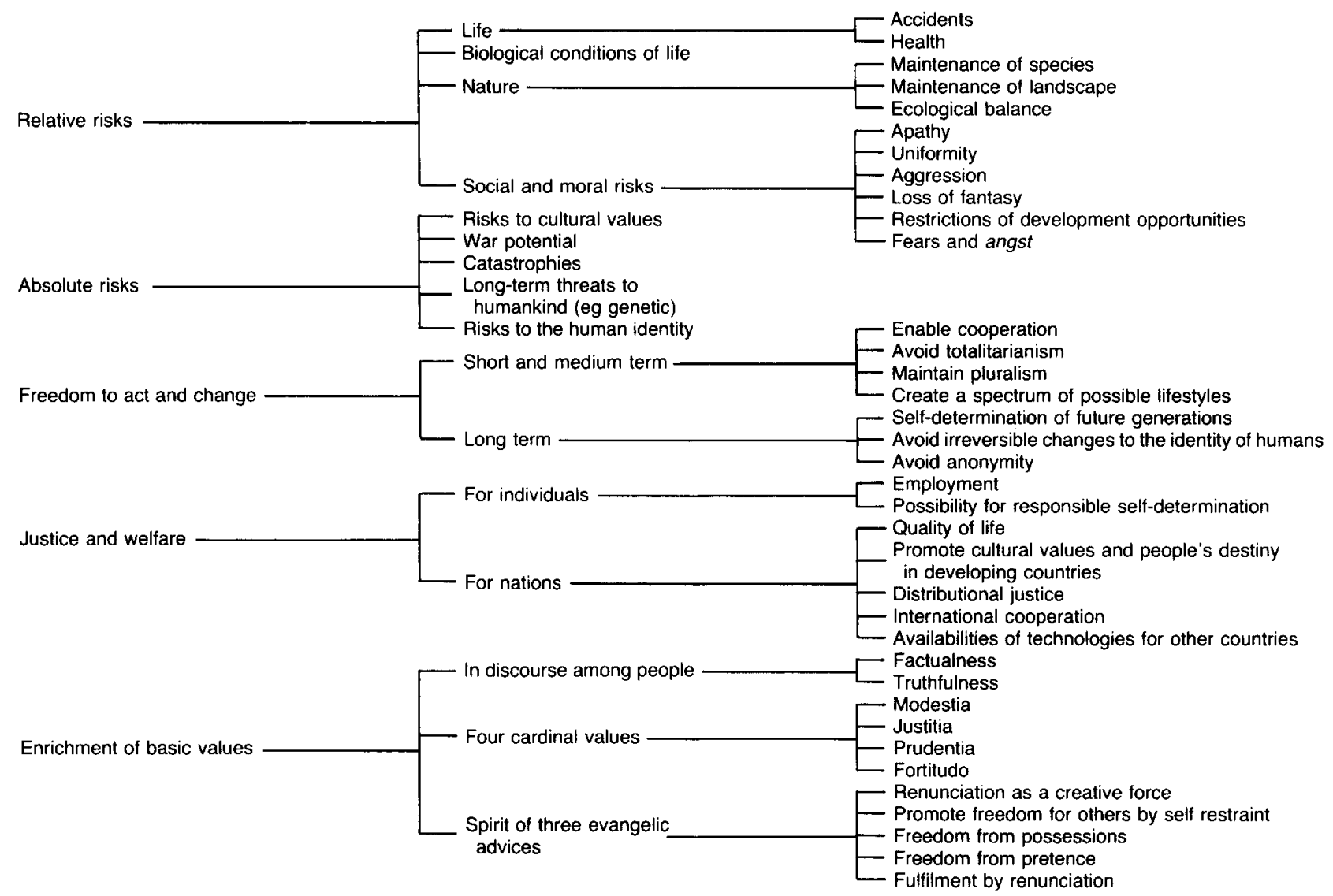

Figure 2. Value tree for the German Catholic Church (DKK).

ity, social compatibility, and international compatibility. The first three general criteria (financial, technical, and material requirements, security of energy supplies, and national economic impacts) cover concerns about the costs, efficiency, security, and market consequences of alternative energy systems. The general criteria concerning impacts on the natural environment and health and safety are self-explanatory. General criteria about social and political impacts describe an array of impacts on culture, social structures, quality of life, options for future generations, democracy and its institutions, as well as characteristics of the process by which energy systems decisions are made. The final general criterion is international impacts, which concerns issues of peace, international distributive justice, and options of international policy.

To construct the combined value tree, we first created a list of all the general criteria of the nine individual trees (Table 1).

We found substantial agreement among groups on these general value categories, although the wording and perhaps the meaning differed somewhat from one group to another. Some overlap existed between energy systems aspects and economics; environment and health/safety; and social and political impacts. For clarity, we defined a general criterion for each of these areas.

This caused no difficulty in the environmental/health area, since the separation between impacts on people and impacts on nature is readily made. In the energy/economics area, a key question was how to structure the direct costs, efficiencies, and the indirect economic 


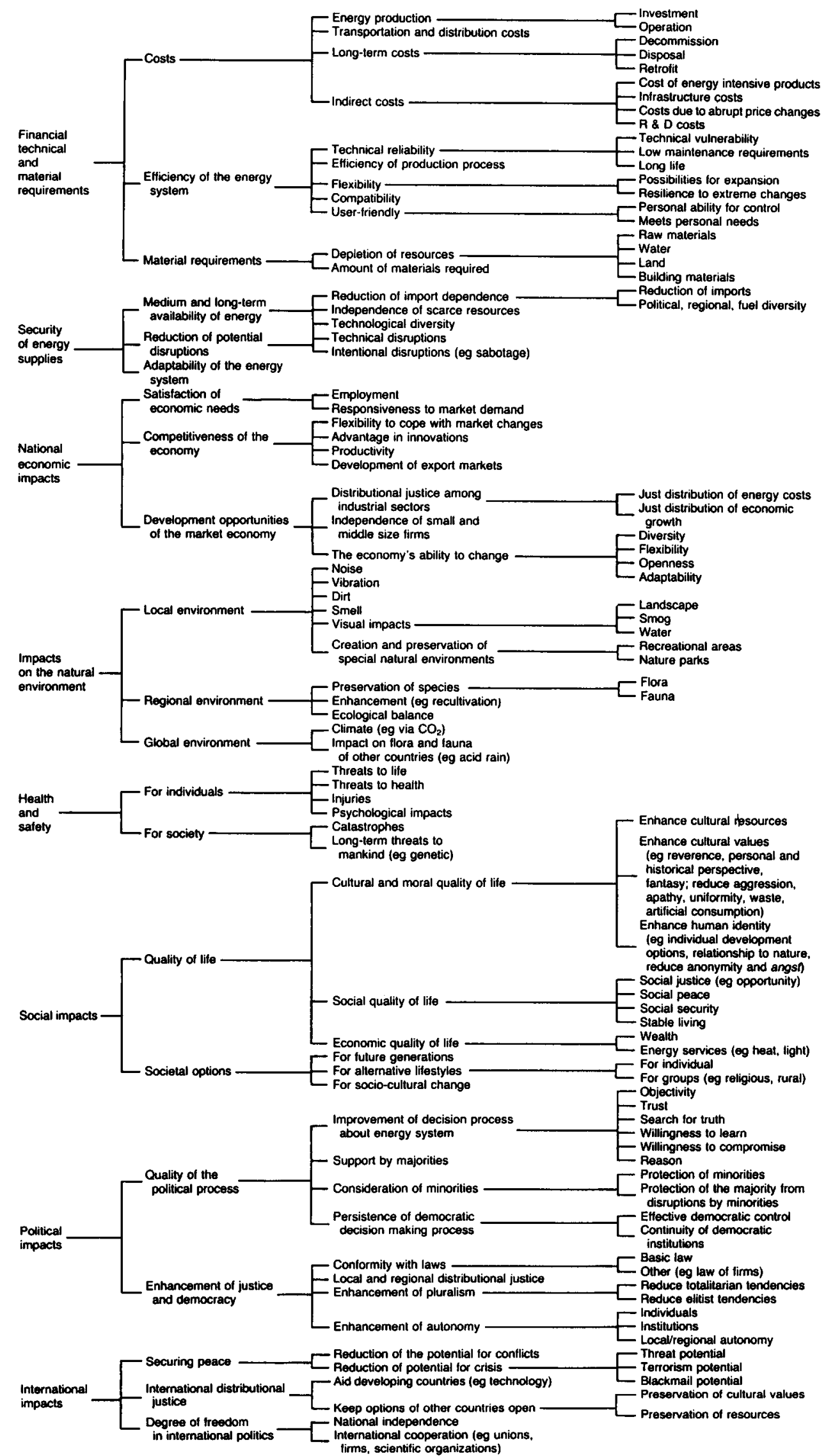

Figure 3. The combined value tree. 
Table 1. General criteria.

Quality of the socio-economic system

Compatibility with the economic system

Economic impacts (twice)

Economic efficiency (twice)

Total economic cost

Development opportunities for the market economy

Energy systems' security

Energy systems' aspects (twice)

Technical systems' aspect

Energy services

Efficiency in the use of resources

Environment and safety

Environmental 'friendliness'

Environmental load (twice)

Environmental compatibility

Environment and health

Relative risks

Absolute risks

Protection of humanity

Protection of nature
Security

Quality of life (twice)

Social impacts

Acceptance

Degrees of freedom

Freedom to act and change

Social compatibility

Socio-political impacts

Efficiency of people, organizations, and administration

Justice (twice)

Justice and welfare

Enhancement of personal values

Quality of interpersonal relationships

Political impacts

International cooperation

International effects (thrice)

World security

International consequences

Quality of international relations

impacts of energy systems. We separated this area into three general criteria: the more direct material and monetary costs, security of energy supply, and the economic implications of the energy system on the market economy. We had some difficulties separating political from social impacts, as some of the former were means for the latter. We finally clustered criteria concerned with the political process under 'political impacts', and criteria concerned with social welfare and social security under 'social impacts'.

In order to elaborate the eight general criteria, we listed the next level criteria (second or third in the individual trees) from all trees, wherever they logically fitted. Except for criteria in the social and political area, we did not have much difficulty in assigning the 85 second and third level criteria to the eight. In this step, choices such as the following were necessary: 'Resource depletion' was moved from the environmental heading to material requirements in order to avoid double counting. And 'Enhancement of cultural resources' was moved from an environmental to a social characterization to maintain the focus on 'Natural environment' in the former category. Many such exchanges between social and political impacts were necessary before a clear separation emerged. In particular, the impacts on democracy and on individual rights which originally appear in both areas, were finally subsumed under 'Political impacts' as a separate criterion.

After such adjustments with the 85 initial 'second level' criteria, we began to cluster them into logical packages. This resulted in the 21 second level criteria illustrated in Figure 3. Some aspects deserve closer attention. The division of 'National economic impacts' into 'Satisfaction of economic needs', 'Competitiveness of the economy' and 'Development opportunities of the market economy' reflects our interpretation of these as impacts on the economic system as a whole. Narrower impacts on energy prices and the costs of energy intensive products are counted under 'Financial, technical, and material requirements'. We separated 'Health and safety' into effects on individuals and effects that potentially threaten a society or even mankind. This separation allows a clearer accounting of catastrophes - once for associated losses of lives, once as fundamental changes in society. We divided social impacts into 
'Quality of life', which covers a broad spectrum from culture to standard of living, and 'Societal options', which relates to maintaining options for individual lifestyles and sociocultural change and for future generations. The breakdown of 'Political impacts' into 'Quality of the political process' and 'Enhancement of justice and democracy' was motivated by several interview partners who stressed that the 'Style of the discussion' about energy alternatives and the quality of the reasoning behind decisions on alternative energy systems should be included in a value tree.

Having created the top two levels of the combined value tree we attached any criteria remaining from the original 85 in appropriate places under the 21 second level criteria, added the remaining substructures of the individual value trees, and repeated the clustering process. In most cases we could utilize substructures of the individual trees for the combined tree with little modification. In this way, we attempted to maintain the content and logic of each individual value tree. Since each group most thoroughly developed concerns relating to its own interests, this procedure also insured that the combined value tree adequately represented the key interests of each group.

Most of the labels in the combined value tree are self-explanatory, but some clarification may be insightful.

\section{Security of energy supplies: political and regional diversity}

To promote import independence, one would not only like to keep imports to a minimum, but also diversify the import sources. Import countries can be diversified regionally to avoid cut-offs due to wars or natural disasters and politically to avoid import cut-offs due to political action.

\section{Financial requirements: costs due to abrupt price changes}

An energy system should support a steady price development. Abrupt price changes have direct costs, but also lead to perturbations of the economy which generate indirect costs. This criterion refers to these indirect costs.

National economic impacts: distributional justice among industrial sectors

Fluctuations in energy prices or availability affect different industries differently. It is desirable that an energy system provides equal opportunities for (or puts an equal burden on) different industrial sectors.

\section{Health and safety: catastrophes}

Catastrophes threaten both individuals and society, perhaps even mankind. Under the 'Catastrophe' label, we cover the repercussions on society and mankind as a whole, as individual fatalities are accounted for under 'Threats to life'.

\section{Political impacts: improvement of decision process}

The energy system is closely linked with the style and the context in which decisions about it are made, and choices among energy options may influence the quality of decision processes. We listed several aspects of quality decision making as criteria, including trust, objectivity, and reason. 
Several criteria from individual value trees are not explicitly included in the combined value tree. Some individual value trees listed 'Cost' as an aspect of 'Economic competitiveness', since cheap energy would enable energy-intensive industries to offer products at more competitive prices. However, since cheap energy is a means to competitiveness in this case, we omitted it, while including competitiveness. 'Costs' is listed separately under 'Financial, technical, and material requirements'.

In the health and safety branches we did not distinguish between normal operations and accidents, as suggested by several individual value trees. From the standpoint of an individual, that separation seemed to be relatively unimportant. From a societal standpoint, large accidents may be more severe than many small accidents or fatalities in normal operations. That aspect. seemed to be covered by the catastrophe criterion.

We did not consider citizens' or politicians' attitudes a criterion for evaluating energy systems, although this criterion was included in several value trees, either explicitly or under the label 'Acceptability'. On one hand attitudes are influenced by many of the criteria in the tree, and are thereby captured. On the other hand, positive attitudes translate into agreement by majorities, a criterion which we did include in the tree.

The DKK and DEK value trees included many moral, ethical, and religious values which appear under the criteria 'Quality of the political process' and 'Enhance cultural values'. We believe this captured the important general values, so the seemingly more specific ones concerning modesty, courage, and poverty were omitted.

There are also examples of criteria that did not appear in any individual value tree or, of course, in the combined value tree. Most notable is the absence of criteria related to national prestige, which may be prominent in value trees for energy systems in other countries.

\section{Uses for the value tree structure}

The combined value tree represents a unique 'snapshot' of the values and concerns of some of the most important social groups in Germany. While the limited number of interviews and the individual perspectives of our interview partners as well as our own biases make it doubtful that the tree completely represents the views of German society, we feel confident that it is reasonably comprehensive. In addition, the process by which the tree was constructed provides it with some political legitimacy, as it is based on inputs from many different perspectives.

If participants in the energy debate (which have not been included in our analysis) agree on the logic and completeness of the combined value tree, then their perspectives about energy systems should relate to one or more of the criteria. That is to say, the value tree defines the range of responsible discourse about impacts of energy systems. If new participants do not agree with the logic or completeness of the value tree, they could suggest improvements and provide reasoning for such. This in itself should improve the quality of the discussion. For example, the criteria under 'Financial, technical, and material requirements' provide specific lists that suggest how to measure the performance of energy systems. Groups involved in the energy debate could discuss and perhaps agree about which of these criteria should be measured, how 
they could be measured, and how such measurements should be aggregated.

After structuring the value tree, there would likely remain conflicts between groups about energy systems. To systematically analyse the remaining conflicts, one could ask members of different groups of society to conduct three tasks: select those criteria from the tree relevant for evaluating energy systems, prioritize the selected criteria, and determine the relative performance (or rankings) of the energy options with respect to each criterion in the value tree. Different results among groups for the first two tasks indicate conflicts about values; different results in the last task indicate disagreements about impacts. Renn $e t a l^{t}$ describe a recent effort using the value tree for studying the evaluation of energy systems by selected members of the German public in the manner described above.

Having identified agreements and disagreements among groups, partial formulation of preliminary value trade-offs among the eight general criteria may aid in devising compromises and seeking joint gains in the negotiation process. To be useful in negotiation or in political bargaining, one need not necessarily go through a quantitative analysis using the entire tree. For example, by explicitly modelling the value trade-offs among the more tangible criteria (eg financial, energy security, environmental impacts), it may be possible to create compromise options. ${ }^{7}$

Perhaps the most sophisticated use of the value tree is in formal evaluation of alternative energy options using multi-attribute utility theory ${ }^{8}$ or measurable value theory. ${ }^{9}$ These evaluations combine the impacts of alternative energy systems with value models of judgments of decision-makers responsible for policy concerning Germany's energy future.

This process begins with an assessment of the alternative energy systems on a comprehensive set of criteria from the value tree. A scale is identified or constructed to measure each of the criteria, ${ }^{10}$ and then the possible impact of each energy system is estimated in terms of the scales. These estimates may be deterministic or probabilistic and would be

${ }^{6}$ O. Renn, H.U. Stegelmann, G. Albrecht and U. Kotte, The Empirical Investigation of Citizens' Preferences with Respect to Four Energy Scenarios, Technical Report, Kernforschungsanlage Jülich, Jülich, West Germany, 1984.

${ }^{7} \mathrm{H}$. Raiffa, The Art and Science of Negotiation, Harvard University Press, Cambridge, MA, USA, 1982.

${ }^{8}$ von Winterfeldt and Edwards, op cit, Ref 3; and Keeney and Raiffa, op cit, Ref 4.

${ }^{9} \mathrm{~J}$. Dyer and R. Sarin, 'Measurable multiattribute value functions', Operations Research, 1979, Vol 27, pp 810-822.

${ }^{10}$ R.L. Keeney, Siting Energy Facilities, Academic Press, New York, NY, 1980.

${ }^{11}$ Keeney and Raiffa, op cit, Ref 4 and Keeney, op cit, Ref 10 based on technical and scientific models, data, and professional judgment. Next, decision-makers must address explicitly the crucial issues involving value trade-offs between criteria by stating how much they are willing to give up in terms of achieving one criterion in exchange for achieving more of another criterion. The question concerns which criteria are more important than others and how much more important. There are logical procedures for specifying the necessary value trade-offs for such problems and these procedures have proven to be useful on many problems involving energy systems. ${ }^{11}$ These procedures are not easy to use nor do they provide a panacea for dealing with values on difficult problems. Quite simply, value issues are exceedingly complex and there are no simple 'solutions' to such problems. But to face the values explicitly and logically seems more useful than to avoid them or deal with them informally. 